\title{
Risk scoring based on expression of long non-coding RNAs can effectively predict survival in hepatocellular carcinoma patients with or without fibrosis
}

\author{
JIAXIANG YE ${ }^{1}$, SIYAO WU $^{1}$, SHAN PAN $^{1}$, JUNQI HUANG $^{2}$ and LIANYING GE ${ }^{1}$ \\ Departments of ${ }^{1}$ Medical Oncology and ${ }^{2}$ Pathology, Guangxi Medical University Cancer Hospital, \\ Nanning, Guangxi 530021, P.R. China
}

Received July 7, 2019; Accepted January 31, 2020

DOI: $10.3892 /$ or.2020.7528

\begin{abstract}
Patients with hepatocellular carcinoma (HCC) have different prognoses depending on whether or not they also have fibrosis. Since long non-coding RNAs (lncRNAs) affect tumor formation and progression, the present study aimed to investigate whether their expression might help predict the survival of patients with HCC. Expression profiles downloaded from The Cancer Genome Atlas database were examined to identify lncRNAs differentially expressed (DElncRNAs) between HCC patients with or without fibrosis. These DElncRNAs were then used to develop a risk scoring system to predict overall survival (OS) or recurrence-free survival (RFS). A total of 142 significant DElncRNAs were identified using data from 135 patients with fibrosis and 72 without fibrosis. For HCC patients with fibrosis, a risk scoring system to predict OS was constructed based on five lncRNAs (AL359853.1, Z93930.3, HOXA-AS3, AL772337.1 and AC012640.3), while the risk scoring system to predict RFS was based on 12 lncRNAs (PLCE1-AS1, Z93930.3, LINC02273, TRBV11-2, HHIP-AS1, AC004687.1, LINC01857, AC004585.1, AP000808.1, CU638689.4, AC090152.1 and AL357060.1). For HCC patients without fibrosis, the risk scoring system to predict OS was established based on seven lncRNAs (LINC00239, AC104971.4, AP006285.2, HOXA-AS3, AC079834.2, NRIR and LINC01929), and the system to predict RFS was based on
\end{abstract}

Correspondence to: Professor Lianying Ge, Department of Medical Oncology, Guangxi Medical University Cancer Hospital, 71 Hedi Road, Nanning, Guangxi 530021, P.R. China

E-mail: gelianying1996@126.com

Abbreviations: IncRNA, long non-coding RNA; HCC, hepatocellular carcinoma; OS, overall survival; RFS, recurrence-free survival; TCGA, The Cancer Genome Atlas; FC, fold change; FDR, false discovery rate; ROC, receiver operating characteristic; KEGG, Kyoto Encyclopedia of Genes and Genomes; BMI, body mass index; AFP, $\alpha$-fetoprotein; HR, hazard ratio; AUC, area under ROC curve

Key words: hepatocellular carcinoma, fibrosis, risk scoring system, long non-coding RNA, survival five lncRNAs (AC021744.1, NRIR, LINC00487, AC005858.1

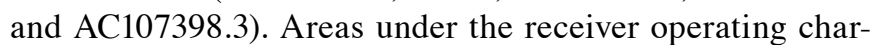
acteristic curves for all risk scoring systems exceeded 0.7. Uni- and multivariate Cox analyses showed that the risk scoring systems were significant independent predictors of OS for HCC patients with fibrosis, or of OS and RFS for HCC patients without fibrosis, after adjusting for clinical factors. Functional enrichment analysis suggested that, depending on the risk scoring system, highly associated genes were involved in pathways mainly associated with the cell cycle, chemokines, Th17 cell differentiation or thermogenesis. The findings of the present study indicate that risk scoring systems based on lncRNA expression can effectively predict the OS of HCC patients with fibrosis as well as the OS or RFS of HCC patients without fibrosis.

\section{Introduction}

Liver cancer was the sixth most commonly diagnosed cancer and the fourth leading cause of cancer deaths worldwide in 2018, with $\sim 841,000$ new cases and 782,000 deaths annually (1). Hepatocellular carcinoma (HCC) is the most frequent primary liver cancer, accounting for $75-85 \%$ of all cases (2). Despite substantial improvements in diagnostic and therapeutic techniques, the overall survival (OS) and recurrence-free survival (RFS) rates of HCC remain comparatively low, mainly because HCC is a highly heterogeneous malignancy $(3,4)$. Furthermore, no effective prognostic biomarkers have yet been described for HCC. Such biomarkers might help to guide individual treatment and improve the prediction of prognosis.

Long non-coding RNAs (lncRNAs), located in the nucleus and cytoplasm of eukaryotic cells, are non-coding transcripts $>200$ nucleotides in length (5). Studies suggest that lncRNAs serve crucial roles in the occurrence and progression of malignant tumors (6-8). For example, one study found that lncRNA-KRTAP5-AS1 and IncRNA-TUBB2A acted as competing endogenous RNAs to influence the function of claudin-4 and thereby affect the prognosis of patients with gastric cancer (9). Specifically, in the case of hepatitis B virus (HBV)-associated HCC, lncRNA HULC can activate HBV by modulating STAT3-related signaling (10). Another study showed that lncRNAlnc-EGFR stimulated the 
differentiation of T-regulatory cells, thus promoting HCC immune evasion (11).

Hepatofibrosis is a type of liver tissue scar reaction involved in chronic liver injury, which can progress to cirrhosis and HCC. Numerous studies have suggested that hepatofibrosis is an important risk factor in HCC (12-14). The recurrence rates and OS of HCC patients are lower in the presence of no or minimal fibrosis (15-17). Therefore, the present study aimed to examine whether IncRNAs may be useful in predicting the survival of HCC patients with or without fibrosis. This possibility was tested using IncRNA expression data from The Cancer Genome Atlas (TCGA).

\section{Material and methods}

Selection of patients with HCC. Expression profiles for lncRNAs and mRNAs, as well as the corresponding clinical information for patients with HCC, were downloaded from TCGA (version 09-14-2017 for HCC) via UCSC Xena (https://xenabrowser. net/datapages/). Patients were included in the present study if i) their HCC was confirmed histologically, ii) complete RNA-Seq data for IncRNAs and mRNAs were available, iii) data on presence or absence of fibrosis were available and iv) survival outcomes were known. Based on the Ishak fibrosis score (18), patients in the TCGA were assigned as having no fibrosis, portal fibrosis, fibrous septum, nodular formation and incomplete cirrhosis, or established cirrhosis. In the present study, patients with 'no fibrosis' were referred to as 'without fibrosis', while all others were referred to as 'with fibrosis'. Finally, 135 HCC patients with fibrosis and 72 without fibrosis were included in the study (Table I). This study complies with TCGA publication guidelines (https://cancergenome.nih. gov/publications/publicationguidelines). Since the data were obtained from TCGA, Guangxi Medical University Cancer Hospital Ethics Committee waived the need for approval.

Expression profile of IncRNAs in HCC. First, lncRNAs with expression levels of 0 in $>50 \%$ of patients were removed, then the remaining lncRNAs were analyzed using the edgeR algorithm within R software (version 3.4.4; www.r-project.org) (19) in order to identify lncRNAs differentially expressed (DElncRNAs) between HCC patients with or without fibrosis. DElncRNAs were defined as those showing $\log _{2}$ fold change $(\log F C) \mid>1$ with a false discovery rate $(F D R)<0.05$. Cluster heat maps and volcano maps were generated using gplots and heatmap packages in $\mathrm{R}$ software.

Construction of IncRNA expression-based risk scoring systems and prognostic assessment. A univariate Cox model was employed to identify the relationships of DElncRNAs with OS or RFS. In this analysis, IncRNAs in relationships associated with $\mathrm{P}<0.05$ were regarded as statistically significant. Multivariate Cox regression analysis was subsequently used to assess the contribution of a lncRNA and to select the best model via a backward stepwise method. A risk scoring system was constructed based on a linear combination of the IncRNA expression level and a multiplied regression coefficient $(\beta)$ : Risk score $=(\beta 1 \mathrm{x}$ expression level of lncRNA1 $)$ $+(\beta 2 \mathrm{x}$ expression level of lncRNA2) $+(\beta 3 \mathrm{x}$ expression level of lncRNA3 $)+(\beta 4 x$ expression level of $\ldots .$.$) .$
This formula was used to calculate the risk score of each patient with HCC. Prognostic performance was assessed based on the sensitivity and specificity of time-dependent receiver operating characteristic (ROC) curves within 3 years. Based on the cut-off of the median risk score, patients with HCC were divided into high- or low-risk groups, as shown by a non-cluster heat map. Kaplan-Meier survival curves predicted to be low or high risk were created for patients with or without fibrosis. All analyses were conducted using R/Bioconductor.

Prognostic significance of the risk scoring system. To confirm the prognostic significance of the risk scoring systems after adjusting for other clinical variables, uni- and multivariate Cox regression analyses were performed. If the results of these analyses were not significant, stratified analyses were performed to identify potential impact factors using the Chi-square test. All these analyses were carried out using SPSS 16.0 (SPSS, Inc.). All reported P-values were two-sided, and $\mathrm{P}<0.05$ was defined as significant. Hepatitis $\mathrm{B}$ and $\mathrm{C}$ were considered together to avoid too many groups influencing the results of the uni- and multivariate analysis.

Co-expression and functional analysis of mRNAs related to lncRNAs in the risk scoring systems. To identify pairs of co-expressed lncRNA and mRNA, Pearson correlation coefficients and the P-value of the z-test were calculated based on the expression value between prognostic IncRNAs in the risk scoring systems and mRNAs in the dataset of 207 patients with HCC. Protein-coding mRNAs showing a IPearson correlation coefficient $>0.30$ and $\mathrm{P}<0.01$ with a given $\operatorname{lncRNA}$ were considered to be highly related to that IncRNA. These mRNAs were subjected to Kyoto Encyclopedia of Genes and Genomes (KEGG) pathway enrichment analysis using the clusterProfiler package in $\mathrm{R}(20)$. $\mathrm{P}<0.05$ was considered to indicate a statistically significant difference in the enrichment analyses.

\section{Results}

DElncRNAs associated with fibrosis in HCC. The present study investigated the expression levels of RNAs in $135 \mathrm{HCC}$ patients with fibrosis and 72 HCC patients without fibrosis. A total of 142 DElncRNAs were identified, including 41 (28.87\%) that were upregulated and $101(71.13 \%)$ that were downregulated. The first 20 up- and downregulated IncRNAs, and their corresponding $\log \mathrm{FC}, \mathrm{P}$-value and FDR values, sorted by P-value, are shown in Table II. The distribution of all DElncRNAs according to the two dimensions of $-\log _{10}$ (FDR) and $\log \mathrm{FC}$ is shown as a volcano map in Fig. 1. The specificity of DElncRNAs was evaluated using a heat map as shown in Fig. 2.

Using DElncRNAs to predict the OS of HCC patients with fibrosis. Univariate Cox analysis was conducted to explore the associations between DElncRNAs and OS in HCC patients with fibrosis. Seven IncRNAs exhibited a significant association with OS: AC012640.3, CU638689.4, AL772337.1, AL359853.1, HOXA-AS3, AL022724.1 and Z93930.3. Multivariate Cox regression confirmed five of these lncRNAs (AL359853.1, Z93930.3, HOXA-AS3, AL772337.1 and AC012640.3) to be 
Table I. Clinicopathological characteristics of 207 hepatocellular carcinoma patients with or without fibrosis.

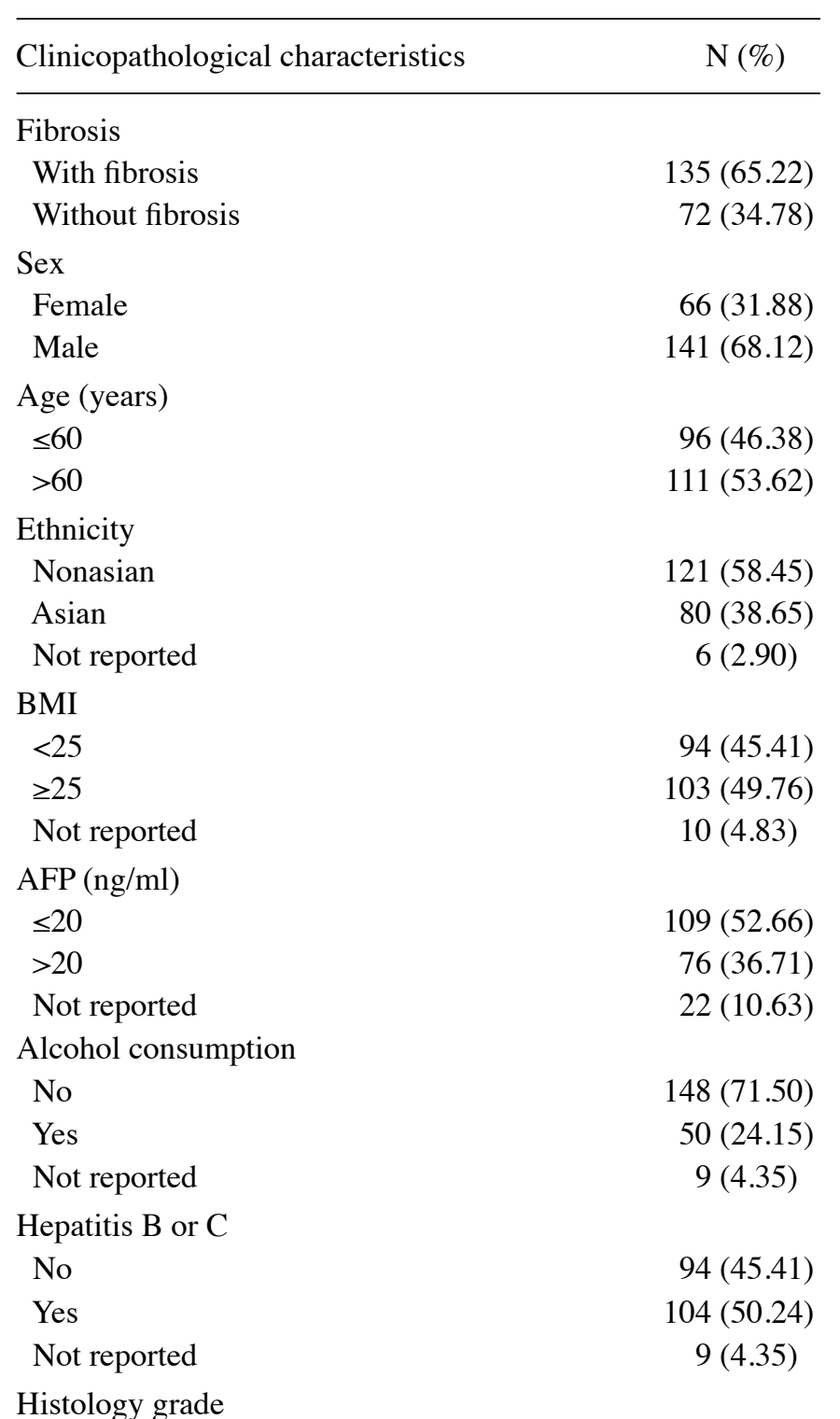

\section{G1-2}

G3-4

Not reported

Pathologic stage

Stage I+II

Stage III+IV

Not reported

New tumor event

No

Yes

Not reported

Cancer status

Tumor free

With tumor

Not reported

Residual tumor

R0

Non-R0

Not reported
Table I. Continued.

\begin{tabular}{lc}
\hline Clinicopathological characteristics & $\mathrm{N}(\%)$ \\
\hline Vascular invasion & \\
Negative & $138(66.67)$ \\
Positive & $60(28.98)$ \\
Not reported & $9(4.35)$ \\
Family cancer history & \\
No & $111(53.62)$ \\
Yes & $68(32.85)$ \\
Not reported & $28(13.53)$
\end{tabular}

BMI, body mass index; AFP, $\alpha$-fetoprotein.

independent predictors of OS (Table III). The final risk scoring system was as follows:

Risk score $=(0.2751 \times$ AL359853.1 $)+(0.5679 \times$ Z93930.3 $)+$ $(0.1861 \times$ HOXA-AS3 $)+(0.2186 \times$ AL772337.1) $+(0.4639 \times$ AC012640.3).

In this prognostic formula, higher expression levels of the five lncRNAs were associated with higher risk of death $(\beta>0)$.

Based on the risk scores for OS, HCC patients with fibrosis were divided into high- or low-risk groups using the median score as a cut-off (Fig. 3A), and Kaplan-Meier curves were calculated for the two groups Fig. 4A. Patients with a high-risk score showed poorer OS than patients with a low-risk score at 3 years (65.4 vs. $86.1 \%)$ and 5 years (28.6 vs. $79.9 \%)$. The area under the ROC curve for the risk scores was 0.732 (Fig. 5A).

Using DElncRNAs to predict the RFS of HCC patients with fibrosis. Uni- and multivariate Cox regression analyses were also performed between the DElncRNAs and RFS of HCC patients with fibrosis. Univariate analysis identified 27 lncRNAs that were significantly associated with RFS: LINC01857, AC090152.1, LINC02407, LINC01970, TRBV11-2, CU638689.4, C20orf166-AS1, AC027348.1, Z93930.3, MEG3, LINC02273, HHIP-AS1, AC004585.1,FZD10-AS1,LINC01215, LINC00239, AP000808.1, PLCE1-AS1, Z99755.3, AL357060.1, 155 (74.88) AC005083.1, MEG9, LINC00473, AC004687.1, AL359853.1, 41 (19.81) LINC02195 and LINC01842. Multivariate analysis confirmed 11 (5.31) the following 12 as independent prognostic indicators of RFS: PLCE1-AS1, Z93930.3, LINC02273, TRBV11-2, HHIP-AS1, AC004687.1, LINC01857, AC004585.1, AP000808.1, CU638689.4, AC090152.1 and AL357060.1 (Table IV). The risk scoring system was as follows:

Risk score $=(-0.4792 \times$ PLCE1-AS1 $)+(0.4315 \times$ Z93930.3 $)+$ $(0.4505 \times$ LINC02273) + (-0.2680 x TRBV11-2) + (-0.1816 x HHIP-AS1 $)+(-0.2211 \times$ AC004687.1) + (-0.3274 x LINC01857) + $(0.2398 \times \mathrm{AC} 004585.1)+(-0.1150 \times \mathrm{AP} 000808.1)+(-0.2929 \times$ CU638689.4) +(-0.2303 x AC090152.1)+(-0.1530 x AL357060.1).

In this formula, higher expression of Z93930.3, LINC02273 and AC004585.1 was associated with higher risk of recurrence $(\beta>0)$, while higher expression of the other lncRNAs was associated with improved RFS $(\beta<0)$. 
Table II. Differentially expressed lncRNAs in hepatocellular carcinoma patients with or without fibrosis.

A, Top 20 upregulated lncRNAs

\begin{tabular}{lclc}
\hline lncRNA & logFC & P-value & FDR \\
\hline AP000439.3 & 5.4751654 & $4.24 \times 10^{-13}$ & $3.03 \times 10^{-10}$ \\
LINC01819 & 5.0170809 & $1.22 \times 10^{-12}$ & $7.60 \times 10^{-10}$ \\
MEG9 & 2.5802684 & $2.10 \times 10^{-8}$ & $4.78 \times 10^{-6}$ \\
FAM30A & 1.9258543 & $3.12 \times 10^{-7}$ & $5.24 \times 10^{-5}$ \\
AC245100.6 & 2.6549937 & $3.52 \times 10^{-7}$ & $5.58 \times 10^{-5}$ \\
LINC02273 & 1.2146603 & $1.68 \times 10^{-6}$ & $2.34 \times 10^{-4}$ \\
AC104971.4 & 2.4240637 & $2.42 \times 10^{-6}$ & $3.21 \times 10^{-4}$ \\
HOXA-AS3 & 1.7517143 & $5.23 \times 10^{-6}$ & $5.85 \times 10^{-4}$ \\
TRBV11-2 & 1.5240872 & $9.87 \times 10^{-6}$ & $9.70 \times 10^{-4}$ \\
NRIR & 1.1734476 & $1.15 \times 10^{-5}$ & $1.09 \times 10^{-3}$ \\
AC004687.1 & 1.0076407 & $3.72 \times 10^{-5}$ & $2.33 \times 10^{-3}$ \\
LINC01857 & 1.0254128 & $3.98 \times 10^{-5}$ & $2.44 \times 10^{-3}$ \\
AC243829.1 & 1.0263797 & $4.79 \times 10^{-5}$ & $2.79 \times 10^{-3}$ \\
LINC00487 & 1.3755637 & $5.39 \times 10^{-5}$ & $3.01 \times 10^{-3}$ \\
LINC01215 & 1.0637294 & $1.15 \times 10^{-4}$ & $5.57 \times 10^{-3}$ \\
MEG3 & 1.4208994 & $1.21 \times 10^{-4}$ & $5.71 \times 10^{-3}$ \\
LINC01549 & 1.5173721 & $1.30 \times 10^{-4}$ & $5.94 \times 10^{-3}$ \\
AC004585.1 & 1.0120319 & $1.45 \times 10^{-4}$ & $6.32 \times 10^{-3}$ \\
LINC01269 & 1.595745 & $1.50 \times 10^{-4}$ & $6.44 \times 10^{-3}$ \\
Z99755.3 & 1.318727 & $1.85 \times 10^{-4}$ & $7.37 \times 10^{-3}$ \\
\hline
\end{tabular}

B, Top 20 downregulated lncRNAs

\begin{tabular}{lccc}
\hline lncRNA & $\log$ FC & P-value & FDR \\
\hline AC139749.1 & -4.63412 & $1.19 \times 10^{-27}$ & $6.80 \times 10^{-24}$ \\
AC069431.1 & -2.66384 & $7.24 \times 10^{-19}$ & $2.07 \times 10^{-15}$ \\
AC007099.1 & -4.01939 & $2.56 \times 10^{-18}$ & $4.87 \times 10^{-15}$ \\
AC022167.4 & -2.49441 & $5.22 \times 10^{-17}$ & $7.45 \times 10^{-14}$ \\
LINC02334 & -3.13188 & $8.87 \times 10^{-15}$ & $1.01 \times 10^{-11}$ \\
LINC01970 & -1.80509 & $1.39 \times 10^{-13}$ & $1.33 \times 10^{-10}$ \\
AL359853.1 & -2.81772 & $1.83 \times 10^{-13}$ & $1.49 \times 10^{-10}$ \\
AL445493.2 & -2.5131 & $1.33 \times 10^{-12}$ & $7.60 \times 10^{-10}$ \\
AL158839.1 & -2.44346 & $1.52 \times 10^{-12}$ & $7.86 \times 10^{-10}$ \\
AC010457.1 & -2.44059 & $9.53 \times 10^{-12}$ & $4.53 \times 10^{-9}$ \\
TH2LCRR & -1.77579 & $3.01 \times 10^{-11}$ & $1.32 \times 10^{-8}$ \\
CCDC13-AS1 & -1.75267 & $7.28 \times 10^{-11}$ & $2.96 \times 10^{-8}$ \\
PLCE1-AS1 & -2.39471 & $1.72 \times 10^{-10}$ & $6.53 \times 10^{-8}$ \\
LINC01686 & -1.62237 & $1.84 \times 10^{-10}$ & $6.57 \times 10^{-8}$ \\
HHATL-AS1 & -2.11296 & $9.54 \times 10^{-10}$ & $3.20 \times 10^{-7}$ \\
AC092159.2 & -1.52149 & $1.44 \times 10^{-9}$ & $4.56 \times 10^{-7}$ \\
AL645608.1 & -1.72757 & $4.16 \times 10^{-9}$ & $1.25 \times 10^{-6}$ \\
BX640514.2 & -2.39457 & $4.87 \times 10^{-9}$ & $1.39 \times 10^{-6}$ \\
AC021744.1 & -2.20589 & $9.84 \times 10^{-9}$ & $2.67 \times 10^{-6}$ \\
AC104031.1 & -1.82197 & $1.12 \times 10^{-8}$ & $2.91 \times 10^{-6}$ \\
\hline & & & \\
\hline
\end{tabular}

lncRNA, long non-coding RNA; $\log F C$, $\log _{2}$ fold change; FDR, false discovery rate.

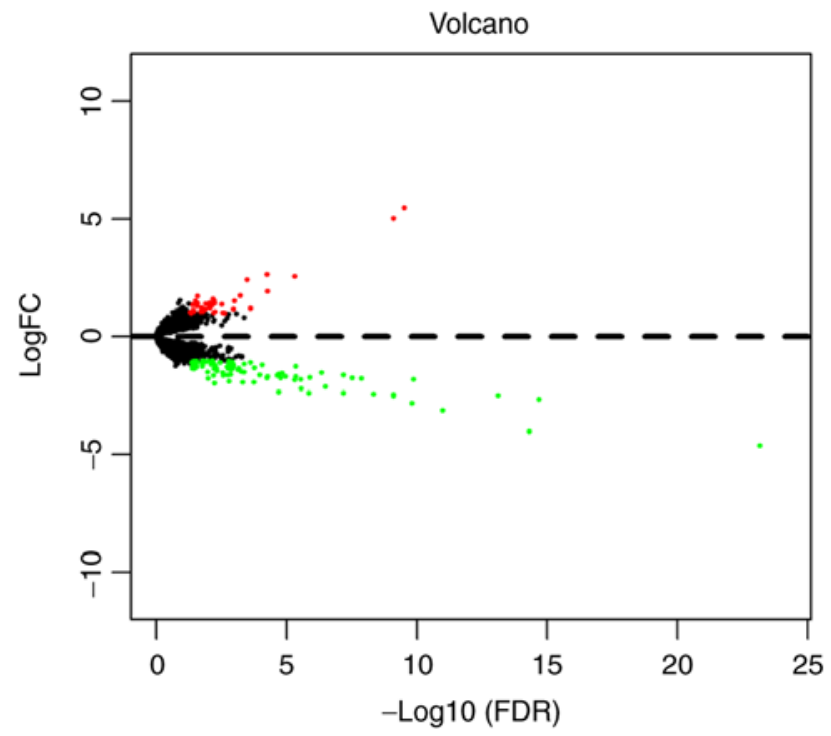

Figure 1. Volcano map of differentially expressed long non-coding RNAs in hepatocellular carcinoma patients with or without fibrosis. Red spots represent upregulated genes; green spots, downregulated genes. FDR, false discovery rate; $\log \mathrm{FC}, \log$ fold change.

HCC patients with fibrosis were stratified into high- or low-risk groups using the median risk score as a cut-off (Fig. 3B), and Kaplan-Meier curves were calculated for both groups (Fig. 4B). Patients with a high-risk score had poorer RFS than patients with a low-risk score at 3 years $(12.59$ vs. $75.20 \%)$ and 5 years $(0.00$ vs. $59.60 \%)$. The area under the ROC curve was 0.902 (Fig. 5B).

Using DElncRNAs to predict the OS of HCC patients without fibrosis. Univariate analysis showed 27 lncRNAs to be significantly associated with OS in HCC patients without fibrosis: FAM27C, AC007099.1, AC005858.1, LINC00239, AC010280.2, LINC02323, AC011383.1, NRIR, AC104971.4, AC004160.1, AL139385.1, AP001271.1, AC237221.1, AC079834.2, AC093583.1, AL049870.3, AP006285.2, AC098869.2, AC004160.2, AL445931.1, AC239803.4, AC009065.2, LINC01269, AP006285.1, HAGLR, HOXA-AS3 and LINC01929. Multivariate analysis confirmed seven of these as independent predictors of OS: LINC00239, AC104971.4, AP006285.2, HOXA-AS3, AC079834.2, NRIR and LINC01929 (Table V). The risk scoring system was as follows:

Risk score $=(0.280 \times$ LINC00239 $)+(0.774 \times$ AC104971.4 $)+$ $(-0.266 \times$ AP006285.2) + (0.362 x HOXA-AS3) + (-0.586 x $\mathrm{AC} 079834.2)+(-0.514 \times \mathrm{NRIR})+(-0.358 \times$ LINC01929)

In the formula, lower expression of LINC00239, AC104971.4 and HOXA-AS3 was associated with worse OS $(\beta>0)$, while higher expression of the remaining lncRNAs was associated with improved OS $(\beta<0)$.

Patients were stratified into low- or high-risk groups using the median risk score groups (Fig. 6A), and Kaplan-Meier curves were calculated (Fig. 4C). The high-risk group had a poorer OS than the low-risk group at 3 years (33.10 vs. $93.10 \%)$ and 5 years (13.20 vs. $88.70 \%)$. The area under the ROC curves was 0.963 (Fig. 5C). 

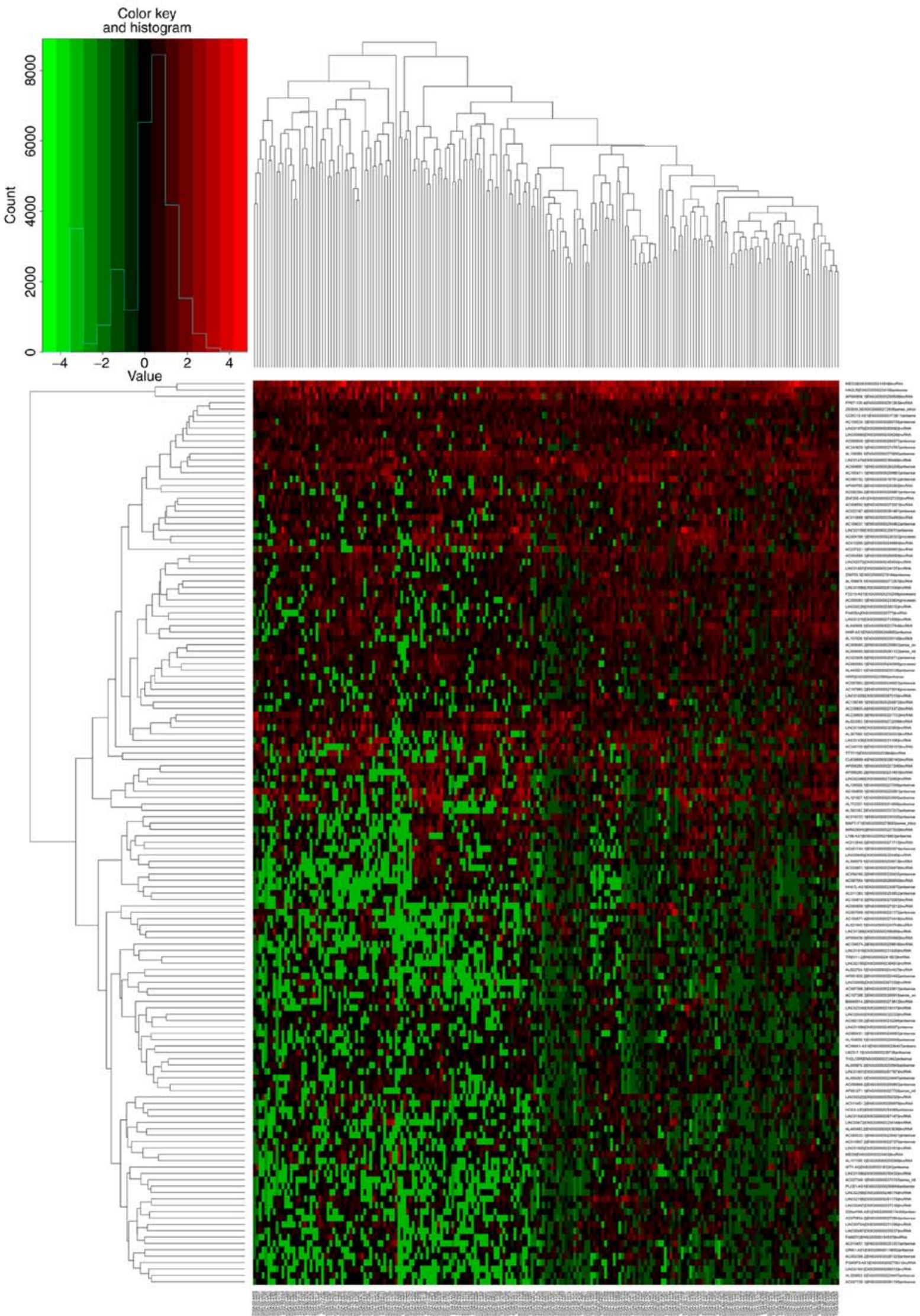

Figure 2. Heat map based on differentially expressed long non-coding RNAs in hepatocellular carcinoma patients with or without fibrosis. Red indicates upregulated long non-coding RNAs and green indicates downregulated ones.

Using DElncRNAs to predict the RFS of HCC patients without fibrosis. Univariate analysis showed six lncRNAs
(NRIR, AC005858.1, LINC00487, AC107398.3, AC021744.1 and BX640514.2) to have a significant association with the 

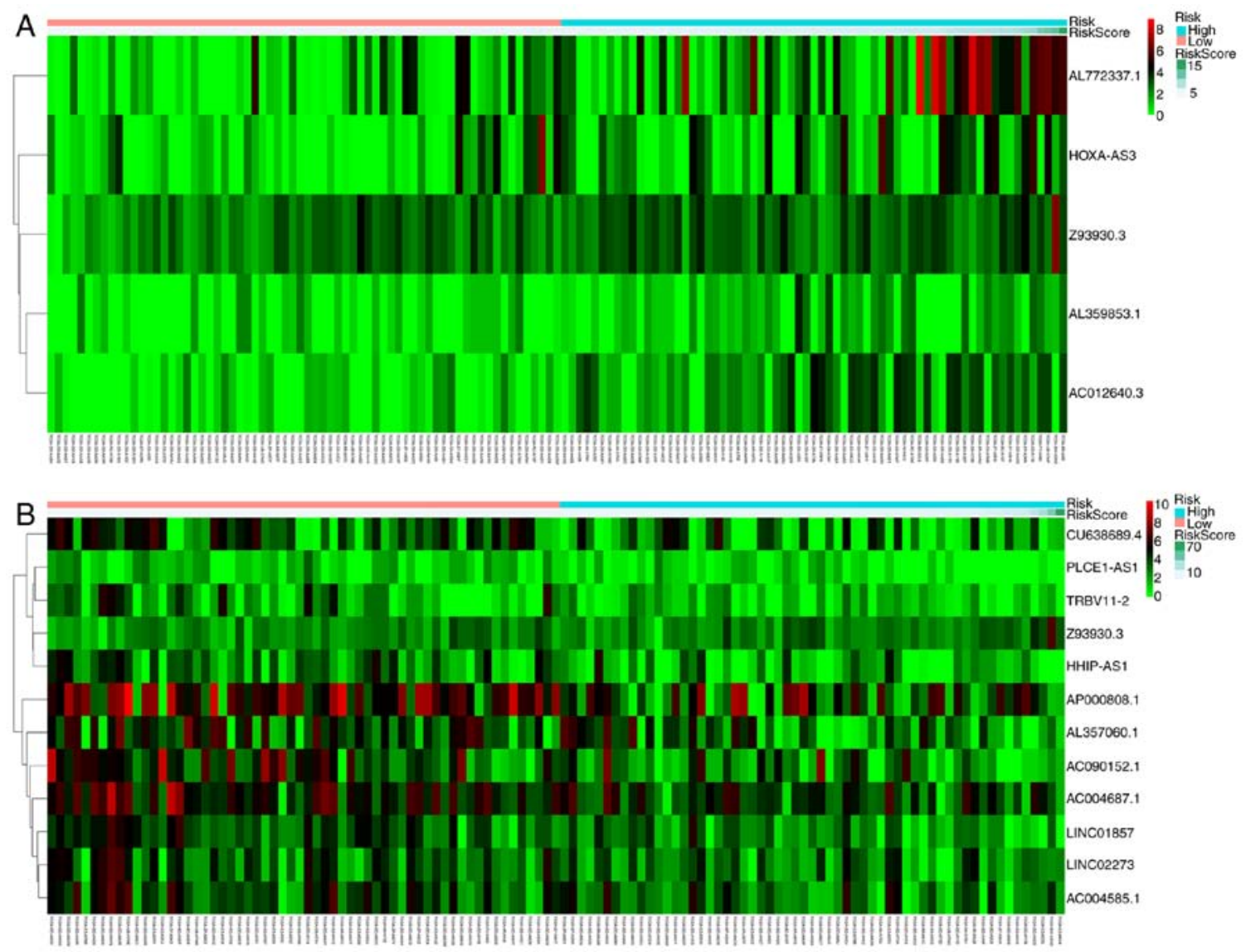

Figure 3. Non-cluster risk heat map of risk scoring systems based on long non-coding RNA expression for (A) overall survival or (B) in recurrence-free survival in hepatocellular carcinoma patients with fibrosis. Risk rises gradually from left to right.
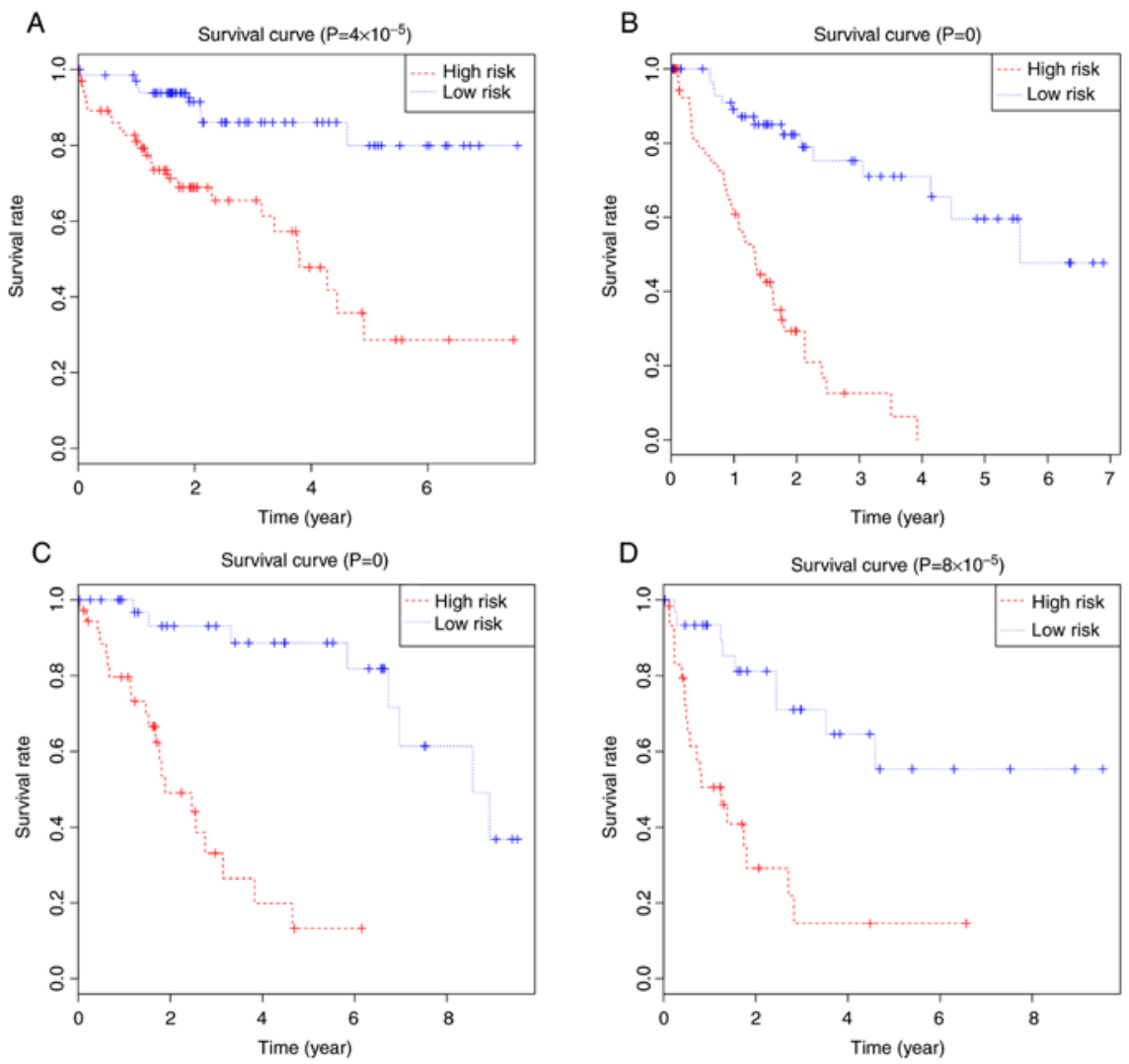

Figure 4. Kaplan-Meier survival curves for (A) OS or (B) RFS of HCC patients with fibrosis, and (C) OS or (D) RFS of HCC patients without fibrosis. Patients were stratified using the median risk score as the cut-off. OS, overall survival; RFS, recurrence-free survival; HCC, hepatocellular carcinoma. 
A

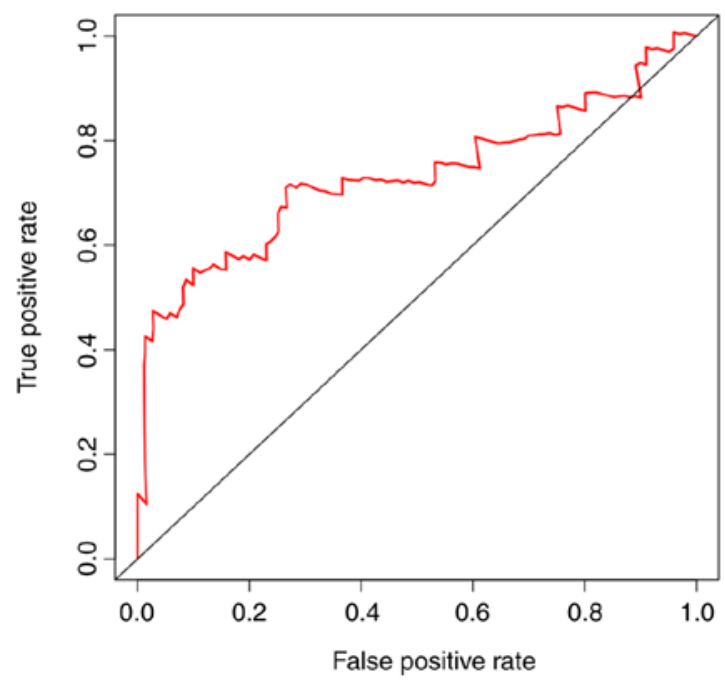

C

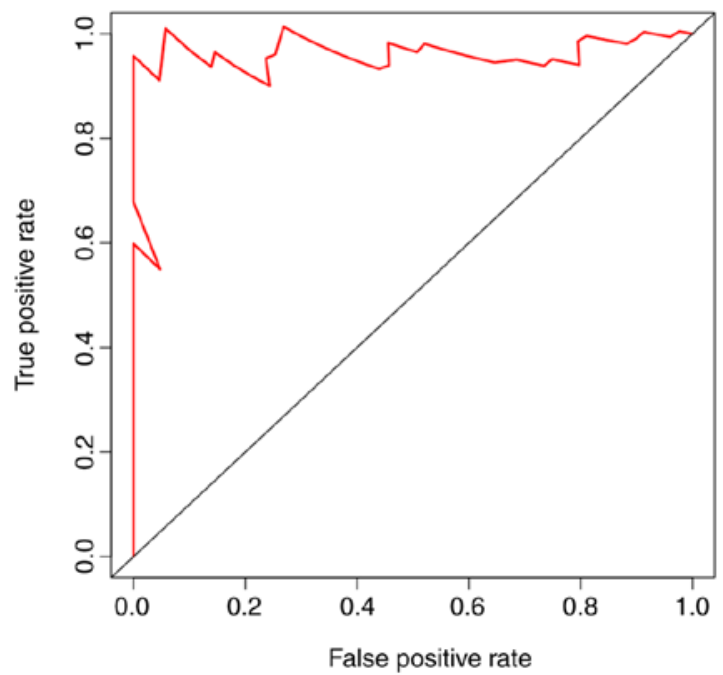

B

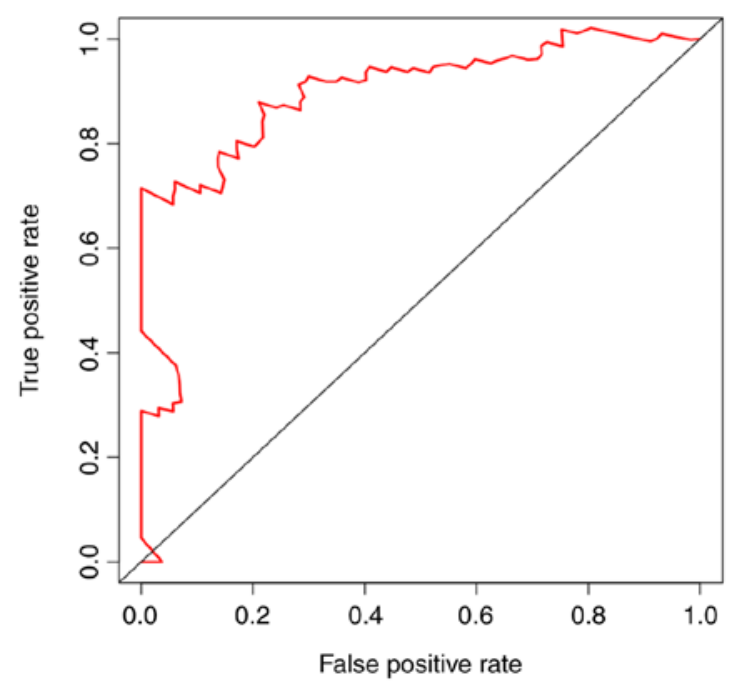

D

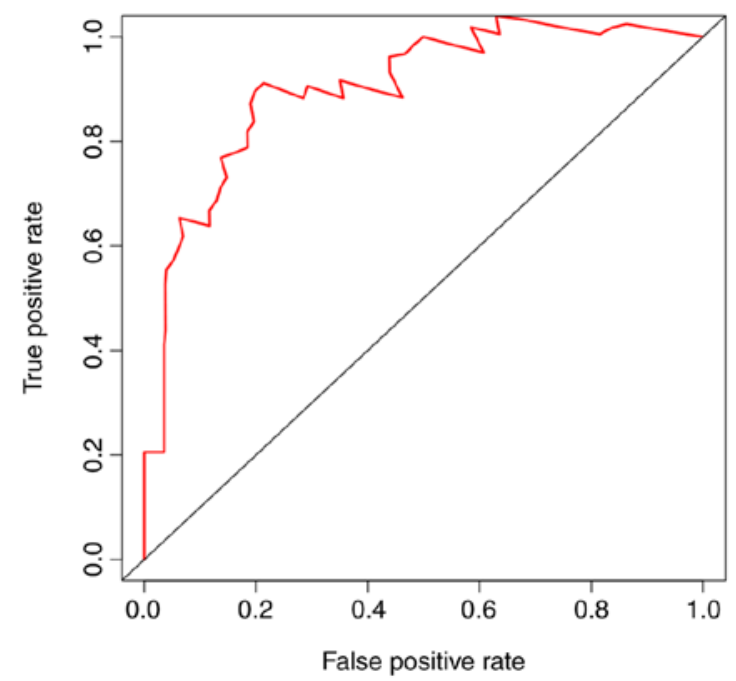

Figure 5. ROC curves describing the ability of long non-coding RNA-based risk scoring systems to predict (A) OS or (B) RFS of HCC patients with fibrosis, and (C) OS or (D) RFS of HCC patients without fibrosis. OS, overall survival; RFS, recurrence-free survival; HCC, hepatocellular carcinoma; ROC, receiver operating characteristic; AUC, area under the curve.

RFS of HCC patients without fibrosis. Multivariate analysis found five lncRNAs to be independent prognostic indicators of RFS: AC021744.1, NRIR, LINC00487, AC005858.1 and AC107398.3 (Table VI). The risk scoring system was as follows:

Risk score $=(0.1430 \times$ AC021744.1 $)+(-0.4181 \times$ NRIR $)+$ $(-0.5324 \times$ LINC00487) $+(0.2145 \times$ AC005858.1) $+(0.2217 \times$ AC107398.3).

Higher expression of AC021744.1, AC005858.1 and AC107398.3 was associated with higher risk of recurrence $(\beta>0)$, while higher expression of the other IncRNAs was associated with improved RFS $(\beta<0)$.

Patients were stratified into high- or low-risk groups using the median risk score as cut-off (Fig. 6B), and Kaplan-Meier curves showed that high-risk patients had poorer RFS than low-risk patients at 3 years (14.6 vs. $71.0 \%)$ and 5 years (14.6 vs. 55.3\%; Fig. 4D). The area under the ROC curves was 0.90 (Fig. 5D).
Prognostic significance of the risk scoring system after adjustment for other clinical characteristics. Each of the four risk scoring systems was validated after adjusting for other clinical characteristics that can influence survival. First, univariate Cox regression analysis was conducted between clinical features and OS for HCC patients with fibrosis. The risk scoring system, age, body mass index (BMI) and ethnicity were significantly associated with OS. The following characteristics were not associated with OS: $\alpha$-fetoprotein (AFP), sex, hepatitis, alcohol consumption, histology grade, new tumor event, pathologic stage, cancer status, family cancer history, residual tumor and vascular invasion. Subsequently, multivariate Cox regression was performed using the covariates that were significant in the univariate analysis. The hazard ratio (HR) of the risk scoring system was 3.92 [95\% confidence interval (CI) 1.32-11.66] in the univariate Cox regression, and 2.65 (95\% CI 1.12-6.26) in the multivariate Cox regression after adjusting for the other clinical covariates. These results confirm that the risk scoring system is a 
Table III. Five IncRNAs associated with the overall survival of hepatocellular carcinoma patients with fibrosis in the best statistical model.

\begin{tabular}{lcccc}
\hline lncRNA & $\beta$ & HR & $\mathrm{z}$ & P-value \\
\hline AL359853.1 & 0.2751 & 1.3167 & 1.66 & 0.09761 \\
Z93930.3 & 0.5679 & 1.7646 & 2.61 & 0.00913 \\
HOXA-AS3 & 0.1861 & 1.2045 & 1.92 & 0.05485 \\
AL772337.1 & 0.2186 & 1.2444 & 2.81 & 0.00499 \\
AC012640.3 & 0.4639 & 1.5902 & 3.65 & 0.00026 \\
\hline
\end{tabular}

lncRNA, long non-coding RNA; HR, hazard ratio.

Table IV. Twelve lncRNAs associated with the recurrence-free survival of hepatocellular carcinoma patients with fibrosis in the best statistical model.

\begin{tabular}{lrcrc}
\hline lncRNA & $\beta$ & $\mathrm{HR}$ & $\mathrm{z}$ & P-value \\
\hline PLCE1-AS1 & -0.4792 & 0.6193 & -2.76 & 0.00587 \\
Z93930.3 & 0.4315 & 1.5396 & 2.53 & 0.01131 \\
LINC02273 & 0.4505 & 1.5690 & 2.19 & 0.02819 \\
TRBV11-2 & -0.2680 & 0.7649 & -1.94 & 0.05275 \\
HHIP-AS1 & -0.1816 & 0.8339 & -1.49 & 0.13637 \\
AC004687.1 & -0.2211 & 0.8016 & -1.66 & 0.09697 \\
LINC01857 & -0.3274 & 0.7208 & -2.08 & 0.03709 \\
AC004585.1 & 0.2398 & 1.2709 & 1.62 & 0.10467 \\
AP000808.1 & -0.1150 & 0.8914 & -1.97 & 0.04861 \\
CU638689.4 & -0.2929 & 0.7461 & -3.40 & 0.00066 \\
AC090152.1 & -0.2303 & 0.7943 & -2.48 & 0.01317 \\
AL357060.1 & -0.1530 & 0.8581 & -2.01 & 0.04431
\end{tabular}

lncRNA, long non-coding RNA; HR, hazard ratio.

Table V. Seven lncRNAs associated with the overall survival of hepatocellular carcinoma patients without fibrosis in the best statistical model.

\begin{tabular}{lcccc}
\hline lncRNA & $\beta$ & HR & \multicolumn{1}{c}{$\mathrm{z}$} & P-value \\
\hline LINC00239 & 0.280 & 1.324 & 2.62 & 0.0088 \\
AC104971.4 & 0.774 & 2.169 & 4.09 & $4.2 \times 10^{-5}$ \\
AP006285.2 & -0.266 & 0.766 & -2.06 & 0.0395 \\
HOXA-AS3 & 0.362 & 1.437 & 1.86 & 0.0633 \\
AC079834.2 & -0.586 & 0.557 & -2.64 & 0.0083 \\
NRIR & -0.514 & 0.598 & -2.95 & 0.0032 \\
LINC01929 & -0.358 & 0.699 & -1.89 & 0.0585 \\
\hline
\end{tabular}

lncRNA, long non-coding RNA; HR, hazard ratio.

significant independent predictor of OS for HCC patients with fibrosis. Multivariate Cox regression identified another two independent predictors: BMI (HR 0.38, 95\% CI 0.16-0.88) and ethnicity (HR 0.20, 95\% CI 0.08-0.51) (Table VII).
Table VI. Five IncRNAs associated with the recurrence-free survival of hepatocellular carcinoma patients without fibrosis in the best statistical model.

\begin{tabular}{lcccc}
\hline IncRNA & $\beta$ & HR & $\mathrm{z}$ & P-value \\
\hline AC021744.1 & 0.1430 & 1.1537 & 1.95 & 0.0514 \\
NRIR & -0.4181 & 0.6583 & -2.14 & 0.0324 \\
LINC00487 & -0.5324 & 0.5872 & -2.10 & 0.0361 \\
AC005858.1 & 0.2145 & 1.2392 & 2.71 & 0.0068 \\
AC107398.3 & 0.2217 & 1.2482 & 2.03 & 0.0421 \\
\hline
\end{tabular}

lncRNA, long non-coding RNA; HR, hazard ratio.

Second, univariate Cox regression analysis was conducted between the clinical features and RFS of patients with HCC and fibrosis. None of the clinical covariates, with the exception of cancer status, were associated with RFS (Table VIII). Stratified analyses were conducted to identify factors affecting the risk scoring system. These factors included age, ethnicity, alcohol consumption, new tumor event, pathology stage and cancer status $(\mathrm{P}<0.05$; Table IX).

Third, univariate Cox regression analysis was conducted between the clinical features and OS of HCC patients without fibrosis. The risk scoring system, BMI, new tumor event and pathology stage were significantly associated with the OS of HCC patients without fibrosis. Multivariate analysis of these covariates identified the risk scoring system (HR 23.15, 95\% CI 5.65-94.91) and pathology stage (HR 3.82, 95\% CI 1.42-10.25) as significant independent predictors of OS (Table X).

Finally, univariate Cox regression analysis was conducted between the clinical features and RFS of HCC patients without fibrosis. The risk scoring system, age, BMI and pathology stage exhibited a significant association with RFS. The remaining factors did not: Ethnicity, AFP, sex, hepatitis, alcohol consumption, histology grade, new tumor event, cancer status, family cancer history, residual tumor and vascular invasion. Multivariate analysis identified the risk scoring system (HR 6.42, 95\% CI 2.62-15.70) and age (HR 0.36, 95\% CI 0.16-0.80) as significant independent predictors of RFS (Table XI).

Co-expression analysis of DElncRNAs and mRNAs, and functional analysis of the mRNAs. Potential co-expression of the lncRNAs in the risk scoring systems and mRNAs in RNA-seq data was explored using Pearson's correlation (Tables SI-SIV). The mRNAs found to be strongly associated with these IncRNAs were then analyzed using KEGG signal pathway databases. The top 10 significantly enriched KEGG signal pathways are shown in Fig. 7. Functional enrichment analysis showed that mRNAs strongly associated with the risk scoring systems are involved mainly in cell cycle-related pathways (in the case of OS of patients with HCC and fibrosis), chemokine-related pathways (RFS of patients with HCC and fibrosis), Th17 cell differentiation-related pathways (OS of HCC patients without fibrosis) and thermogenesis-related pathways (RFS of HCC patients without fibrosis). 
Table VII. Uni- and multivariate Cox regression analysis of factors affecting overall survival in hepatocellular carcinoma patients with fibrosis.

\begin{tabular}{|c|c|c|c|c|c|c|c|c|}
\hline \multirow{3}{*}{$\begin{array}{l}\text { Variables } \\
\text { Risk score (high/low) }\end{array}$} & \multicolumn{4}{|c|}{ Univariate Cox regression } & \multicolumn{4}{|c|}{ Multivariate Cox regression } \\
\hline & \multirow{2}{*}{$\begin{array}{c}\text { P-value } \\
0.01\end{array}$} & \multirow{2}{*}{$\begin{array}{l}\text { HR } \\
3.92\end{array}$} & \multicolumn{2}{|c|}{$95 \% \mathrm{CI}$} & \multirow{2}{*}{$\frac{\text { P-value }}{0.03}$} & \multirow{2}{*}{$\begin{array}{l}\text { HR } \\
2.65\end{array}$} & \multicolumn{2}{|c|}{$95 \% \mathrm{CI}$} \\
\hline & & & 1.32 & 11.66 & & & 1.12 & 6.26 \\
\hline Age $(>60 / \leq 60$ years $)$ & 0.01 & 3.41 & 1.31 & 8.89 & & & & \\
\hline BMI & 0.01 & & & & & & & \\
\hline$<25$ & & & Ref. & & & & Ref. & \\
\hline$\geq 25$ & & 0.26 & 0.07 & 0.89 & 0.02 & 0.38 & 0.16 & 0.88 \\
\hline Not reported & & 1.71 & 0.25 & 11.75 & 0.51 & 1.41 & 0.51 & 3.88 \\
\hline Ethnicity & 0.01 & & & & & & & \\
\hline Non-Asian & & & Ref. & & & & Ref. & \\
\hline Asian & & 0.16 & 0.05 & 0.51 & $<0.01$ & 0.20 & 0.08 & 0.51 \\
\hline $\mathrm{AFP}(\mathrm{ng} / \mathrm{ml})$ & 0.64 & & & & & & & \\
\hline$\leq 20$ & & & Ref. & & & & & \\
\hline$>20$ & & 0.99 & 0.33 & 2.99 & & & & \\
\hline Not reported & & 0.32 & 0.03 & 3.69 & & & & \\
\hline Sex (male/female) & 0.87 & 0.90 & 0.26 & 3.11 & & & & \\
\hline Hepatitis B or C & 0.44 & & & & & & & \\
\hline No & & & Ref. & & & & & \\
\hline Yes & & 1.90 & 0.58 & 6.24 & & & & \\
\hline Not reported & & 0.30 & 0.01 & 11.80 & & & & \\
\hline Alcohol consumption (yes/no) & 0.45 & 0.61 & 0.17 & 2.20 & & & & \\
\hline Histology grade & 0.26 & & & & & & & \\
\hline G1-2 & & & Ref. & & & & & \\
\hline G3-4 & & 2.11 & 0.86 & 5.17 & & & & \\
\hline New tumor event & 0.46 & & & & & & & \\
\hline No & & & Ref. & & & & & \\
\hline Yes & & 0.76 & 0.18 & 3.15 & & & & \\
\hline Not reported & & 3.88 & 0.20 & 73.85 & & & & \\
\hline Pathologic stage & 0.37 & & & & & & & \\
\hline Stage I+II & & & Ref. & & & & & \\
\hline Stage III+IV & & 0.39 & 0.11 & 1.46 & & & & \\
\hline Not reported & & 0.84 & 0.08 & 8.49 & & & & \\
\hline Cancer status & 0.14 & & & & & & & \\
\hline Tumor free & & & Ref. & & & & & \\
\hline With tumor & & 3.04 & 0.84 & 10.98 & & & & \\
\hline Not reported & & 7.77 & 0.26 & 236.32 & & & & \\
\hline Family cancer history & 0.45 & & & & & & & \\
\hline No & & & Ref. & & & & & \\
\hline Yes & & 2.06 & 0.64 & 6.56 & & & & \\
\hline Not reported & & 1.05 & 0.18 & 5.96 & & & & \\
\hline Residual tumor & 0.67 & & & & & & & \\
\hline R0 & & & Ref. & & & & & \\
\hline Non-R0 & & 2.39 & 0.35 & 16.25 & & & & \\
\hline Vascular invasion & 0.16 & & & & & & & \\
\hline Negative & & & Ref. & & & & & \\
\hline Positive & & 2.48 & 0.92 & 6.68 & & & & \\
\hline Not reported & & 2.39 & 0.53 & 10.73 & & & & \\
\hline
\end{tabular}

BMI, body mass index; AFP, $\alpha$-fetoprotein; HR, hazard ratio; CI, confidence interval; Ref., reference. 
Table VIII. Univariate Cox regression analysis of factors affecting recurrence-free survival in hepatocellular carcinoma patients with fibrosis.

\begin{tabular}{|c|c|c|c|c|}
\hline \multirow{3}{*}{$\begin{array}{l}\text { Variables } \\
\text { Risk score (high/low) }\end{array}$} & \multicolumn{4}{|c|}{ Univariate Cox regression } \\
\hline & P-value & HR & & \\
\hline & 0.15 & 2.25 & 0.75 & 6.81 \\
\hline Age (>60/ 660 years $)$ & 0.17 & 0.58 & 0.26 & 1.27 \\
\hline $\begin{array}{r}\text { BMI } \\
<25\end{array}$ & 0.08 & & & \\
\hline$\geq 25$ & & 0.30 & 0.10 & 0.87 \\
\hline Not reported & & 0.17 & 0.01 & 2.66 \\
\hline $\begin{array}{l}\text { Ethnicity } \\
\text { Non-Asian }\end{array}$ & 0.87 & & & \\
\hline Asian & & 0.76 & 0.27 & 2.15 \\
\hline $\begin{array}{l}\operatorname{AFP}(\mathrm{ng} / \mathrm{ml}) \\
\leq 20\end{array}$ & 0.38 & & & \\
\hline$>20$ & & 1.52 & 0.65 & 3.55 \\
\hline Not reported & & 2.94 & 0.52 & 16.58 \\
\hline Sex (male/female) & 0.33 & 0.56 & 0.17 & 1.80 \\
\hline $\begin{array}{l}\text { Hepatitis B or C } \\
\text { No }\end{array}$ & 0.37 & & & \\
\hline Yes & & 0.78 & 0.20 & 3.07 \\
\hline Not reported & & 0.28 & 0.04 & 2.10 \\
\hline Alcohol consumption (yes/no) & 0.36 & 1.84 & 0.51 & 6.65 \\
\hline $\begin{array}{l}\text { Histology grade } \\
\text { G1-2 }\end{array}$ & 0.30 & & & \\
\hline G3-4 & & 0.75 & 0.30 & 1.86 \\
\hline Not reported & & 12.31 & 0.41 & 371.37 \\
\hline New tumor event (yes/no) & 0.84 & $3.51 \times 10^{5}$ & 0.00 & $2.15 \times 10^{59}$ \\
\hline $\begin{array}{l}\text { Pathologic stage } \\
\text { Stage I+II }\end{array}$ & 0.55 & & & \\
\hline Stage III+IV & & 1.63 & 0.50 & 5.30 \\
\hline Not reported & & 0.50 & 0.04 & 6.68 \\
\hline $\begin{array}{l}\text { Cancer status } \\
\text { Tumor free }\end{array}$ & $<0.05$ & & & \\
\hline With tumor & & 3.82 & 1.32 & 11.07 \\
\hline Not reported & & 4.60 & 0.00 & . \\
\hline $\begin{array}{l}\text { Family cancer history } \\
\text { No }\end{array}$ & 0.36 & & & \\
\hline Yes & & 0.56 & 0.19 & 1.66 \\
\hline Not reported & & 0.41 & 0.12 & 1.50 \\
\hline $\begin{array}{l}\text { Residual tumor } \\
\text { R0 }\end{array}$ & 0.85 & & & \\
\hline Non-R0 & & 1.70 & 0.26 & 11.08 \\
\hline Not reported & & 1.39 & 0.08 & 23.58 \\
\hline $\begin{array}{l}\text { Vascular invasion } \\
\text { Negative }\end{array}$ & 0.26 & & & \\
\hline Positive & & 2.08 & 0.75 & 5.77 \\
\hline Not reported & & 0.94 & 0.14 & 6.18 \\
\hline
\end{tabular}


Table IX. Stratified analyses to explore factors influencing the relationship between the risk scoring system and recurrence-free survival in hepatocellular carcinoma patients with fibrosis.

\begin{tabular}{|c|c|c|c|}
\hline \multirow[b]{2}{*}{ Variables } & \multicolumn{2}{|c|}{ Risk score } & \multirow[b]{2}{*}{ P-value } \\
\hline & Low-risk (n) & High-risk (n) & \\
\hline Age (years) & & & $<0.01$ \\
\hline$\leq 60$ & 40 & 23 & \\
\hline$>60$ & 20 & 36 & \\
\hline BMI & & & 0.19 \\
\hline$<25$ & 32 & 23 & \\
\hline$\geq 25$ & 27 & 32 & \\
\hline Ethnicity & & & 0.01 \\
\hline Non-Asian & 20 & 34 & \\
\hline Asian & 38 & 25 & \\
\hline AFP (ng/ml) & & & 0.33 \\
\hline$\leq 20$ & 31 & 36 & \\
\hline$>20$ & 24 & 19 & \\
\hline Sex & & & 0.54 \\
\hline Female & 15 & 12 & \\
\hline Male & 45 & 47 & \\
\hline Hepatitis B or C & & & 0.08 \\
\hline No & 12 & 20 & \\
\hline Yes & 47 & 37 & \\
\hline Alcohol consumption & & & 0.03 \\
\hline No & 47 & 35 & \\
\hline Yes & 12 & 22 & \\
\hline Histology grade & & & 0.20 \\
\hline G1-2 & 42 & 34 & \\
\hline G3-4 & 18 & 24 & \\
\hline New tumor event & & & $<0.01$ \\
\hline No & 45 & 19 & \\
\hline Yes & 15 & 40 & \\
\hline Pathologic stage & & & 0.03 \\
\hline Stage I+II & 52 & 42 & \\
\hline Stage III+IV & 5 & 13 & \\
\hline Cancer status & & & $<0.01$ \\
\hline Tumor free & 48 & 23 & \\
\hline With tumor & 11 & 36 & \\
\hline Family cancer history & & & 0.78 \\
\hline No & 37 & 35 & \\
\hline Yes & 15 & 16 & \\
\hline Residual tumor & & & 0.13 \\
\hline R0 & 58 & 52 & \\
\hline Non-R0 & 2 & 6 & \\
\hline Vascular invasion & & & 0.65 \\
\hline Negative & 41 & 36 & \\
\hline Positive & 17 & 18 & \\
\hline
\end{tabular}

Data are based on the Chi-square test. BMI, body mass index; AFP, $\alpha$-fetoprotein.

\section{Discussion}

HCC has a high morbidity and mortality $(1,2)$, the risk of which differs depending on whether fibrosis is present or not (15-17). Thus, prognostic biomarkers specific for each situation are required in order to improve patient management. Toward this end, the present study explored lncRNAs in patients with HCC that are differentially expressed in the presence or absence of fibrosis, and then identified which of the DElncRNAs used to construct risk scoring systems may be useful for predicting survival. The risk scoring systems were validated using uni- and multivariate Cox analyses following adjustment for several clinical characteristics that can also influence survival.

It was possible to predict the risk of OS for HCC patients with or without fibrosis using 5 or 7 lncRNAs. The areas under the ROC curves were 0.732 or 0.963 , respectively, suggesting reasonable predictive power. Furthermore, multivariate Cox analysis identified additional significant predictors of OS: BMI and ethnicity among patients with fibrosis, or pathology stage among patients without fibrosis. Other studies have also associated these factors with OS in patients with $\operatorname{HCC}(21,22)$.

The present study predicted the RFS of HCC patients without fibrosis using 5 lncRNAs. The area under the ROC curve was 0.90 , suggesting good predictive ability. Multivariate Cox analysis further identified age as a significant independent predictor. The DElncRNA-based risk scoring approach used in the present study was less successful in predicting the RFS of patients with fibrosis. Univariate Cox analysis failed to show that the risk scoring system could significantly predict prognosis after adjusting for other clinical factors. Stratified analyses based on risk scoring identified the following factors as influencing risk: age, ethnicity, alcohol consumption, new tumor event, pathology stage and cancer status. Therefore, these factors need to be taken into account in the prediction of RFS for HCC patients with fibrosis.

The present study identified several DElncRNAs that may be useful targets in efforts to understand why prognosis of patients with $\mathrm{HCC}$ is worse in the presence of fibrosis. Numerous studies have shown improved survival outcomes among patients with no or mild fibrosis than among those with severe fibrosis (15-17), including one analysis of 11,783 patients with HCC (23). It is even possible that fibrosis promotes genetic mutations in patients with HCC (14).

As a first step towards using the DElncRNAs identified in the present study to understand the prognosis more clearly, the molecular functions of protein-coding genes highly associated with the lncRNAs included in the present study's risk scoring systems were analyzed. KEGG pathway analysis showed these genes to be involved mainly in the cell cycle, chemokine-related pathways, Th17 cell differentiation or thermogenesis, depending on whether fibrosis was present and depending on whether OS or RFS was the target outcome. These differential results for HCC subpopulations may help guide future research in understanding, predicting and managing recurrence and fibrosis.

Several previous studies have also constructed risk scoring systems to predict the prognosis of patients with HCC (24-31). However, those risk scoring systems were based on DElncRNAs between HCC and normal samples, while the risk scoring systems in the present study are based on the DElncRNAs between HCC 
Table X. Uni- and multivariate Cox regression analysis of factors affecting overall survival in hepatocellular carcinoma patients without fibrosis.

\begin{tabular}{|c|c|c|c|c|c|c|c|c|}
\hline \multirow{3}{*}{$\begin{array}{l}\text { Variables } \\
\text { Risk score (high/low) }\end{array}$} & \multicolumn{4}{|c|}{ Univariate Cox regression } & \multicolumn{4}{|c|}{ Multivariate Cox regression } \\
\hline & \multirow{2}{*}{$\begin{array}{c}\text { P-value } \\
<0.01\end{array}$} & \multirow{2}{*}{$\begin{array}{l}\text { HR } \\
56.17\end{array}$} & \multicolumn{2}{|c|}{$95.0 \% \mathrm{CI}$} & \multirow{2}{*}{$\begin{array}{c}\text { P-value } \\
<0.01\end{array}$} & \multirow{2}{*}{$\begin{array}{c}\mathrm{HR} \\
23.15\end{array}$} & \multicolumn{2}{|c|}{$95.0 \% \mathrm{CI}$} \\
\hline & & & 8.42 & 374.46 & & & 5.65 & 94.91 \\
\hline Age $(>60 / \leq 60$ years $)$ & 0.37 & 0.45 & 0.08 & 2.62 & & & & \\
\hline BMI & 0.01 & & & & & & & \\
\hline$<25$ & & & Ref. & & & & Ref. & \\
\hline$\geq 25$ & & 2.33 & 0.42 & 12.98 & 0.99 & 1.00 & 0.41 & 2.44 \\
\hline Not reported & & 46.08 & 3.34 & 635.97 & 0.03 & 8.16 & 1.29 & 51.68 \\
\hline Ethnicity & 0.10 & & & & & & & \\
\hline Non-Asian & & & Ref. & & & & & \\
\hline Asian & & 49.26 & 0.68 & $3,591.00$ & & & & \\
\hline Not reported & & 0.20 & 0.00 & 16.50 & & & & \\
\hline $\mathrm{AFP}(\mathrm{ng} / \mathrm{ml})$ & 0.51 & & & & & & & \\
\hline$\leq 20$ & & & Ref. & & & & & \\
\hline$>20$ & & 0.88 & 0.15 & 5.21 & & & & \\
\hline Not reported & & 1.92 & 0.47 & 7.87 & & & & \\
\hline Sex (male/female) & 0.37 & 0.48 & 0.10 & 2.40 & & & & \\
\hline Hepatitis B or C & 0.66 & & & & & & & \\
\hline No & & & Ref. & & & & & \\
\hline Yes & & 3.81 & 0.21 & 68.88 & & & & \\
\hline Not reported & & 0.01 & 0.00 & $4.95 \times 10^{80}$ & & & & \\
\hline Alcohol consumption (yes/no) & 0.06 & 6.99 & 0.90 & 54.44 & & & & \\
\hline Histology grade & 0.12 & & & & & & & \\
\hline G1-2 & & & Ref. & & & & & \\
\hline G3-4 & & 2.29 & 0.50 & 10.51 & & & & \\
\hline Not reported & & 0.00 & 0.00 & 1.44 & & & & \\
\hline New tumor event & $<0.01$ & & & & & & & \\
\hline No & & & Ref. & & & & Ref. & \\
\hline Yes & & 0 & 0 & $5.76 \times 10^{83}$ & 0.90 & 1.07 & 0.38 & 3.05 \\
\hline Not reported & & $1,014.00$ & 18.59 & $55,300.00$ & $<0.01$ & 8.53 & 2.46 & 29.63 \\
\hline Pathologic stage & $<0.01$ & & & & & & & \\
\hline Stage I+II & & & Ref. & & & & Ref. & \\
\hline Stage III+IV & & 2.19 & 0.51 & 9.47 & 0.01 & 3.82 & 1.42 & 10.25 \\
\hline Not reported & & $1,093.00$ & 17.61 & $67,880.00$ & 0.15 & 3.37 & 0.65 & 17.56 \\
\hline Cancer status & 0.13 & & & & & & & \\
\hline Tumor free & & & Ref. & & & & & \\
\hline With tumor & & $131,600.00$ & 0.00 & $3.82 \times 10^{92}$ & & & & \\
\hline Not reported & & 0.00 & 0.00 & 0.80 & & & & \\
\hline Family cancer history & 0.30 & & & & & & & \\
\hline No & & & Ref. & & & & & \\
\hline Yes & & 4.90 & 0.67 & 36.05 & & & & \\
\hline Not reported & & 2.08 & 0.14 & 31.22 & & & & \\
\hline Residual tumor & 0.84 & & & & & & & \\
\hline R0 & & & Ref. & & & & & \\
\hline Non-R0 & & 0.13 & 0.00 & 113.04 & & & & \\
\hline Vascular invasion & 0.08 & & & & & & & \\
\hline Negative & & & Ref. & & & & & \\
\hline Positive & & 6.24 & 0.80 & 48.34 & & & & \\
\hline
\end{tabular}

BMI, body mass index; AFP, $\alpha$-fetoprotein; HR, hazard ratio; CI, confidence interval; Ref., reference. 
Table XI. Uni- and multivariate Cox regression analysis of factors affecting recurrence-free survival in hepatocellular carcinoma patients without fibrosis.

\begin{tabular}{|c|c|c|c|c|c|c|c|c|}
\hline \multirow{3}{*}{$\begin{array}{l}\text { Variables } \\
\text { Risk score (high/low) }\end{array}$} & \multicolumn{4}{|c|}{ Univariate Cox regression } & \multicolumn{4}{|c|}{ Multivariate Cox regression } \\
\hline & \multirow{2}{*}{$\frac{\text { P-value }}{0.01}$} & \multirow{2}{*}{$\begin{array}{l}\mathrm{HR} \\
11.52\end{array}$} & \multicolumn{2}{|r|}{$95 \% \mathrm{CI}$} & \multirow{2}{*}{$\begin{array}{c}\text { P-value } \\
<0.01\end{array}$} & \multirow{2}{*}{$\begin{array}{l}\mathrm{HR} \\
6.42\end{array}$} & \multicolumn{2}{|c|}{$95 \% \mathrm{CI}$} \\
\hline & & & 1.70 & 78.15 & & & 2.62 & 15.70 \\
\hline Age $(>60 / \leq 60$ years $)$ & 0.01 & 0.06 & 0.01 & 0.56 & 0.01 & 0.36 & 0.16 & 0.80 \\
\hline BMI & 0.01 & & & & & & & \\
\hline$<25$ & & & Ref. & & & & & \\
\hline$\geq 25$ & & 1.53 & 0.31 & 7.48 & & & & \\
\hline Not reported & & 221.65 & 6.47 & $7,597.00$ & & & & \\
\hline Ethnicity & 0.69 & & & & & & & \\
\hline Non-Asian & & & Ref. & & & & & \\
\hline Asian & & 1.54 & 0.00 & $7.83 \times 10^{51}$ & & & & \\
\hline Not reported & & 6.48 & 0.09 & 471.12 & & & & \\
\hline $\mathrm{AFP}(\mathrm{ng} / \mathrm{ml})$ & 0.34 & & & & & & & \\
\hline$\leq 20$ & & & Ref. & & & & & \\
\hline$>20$ & & 2.41 & 0.37 & 15.84 & & & & \\
\hline Not reported & & 12.05 & 0.35 & 415.85 & & & & \\
\hline Sex (male/female) & 0.12 & 0.11 & 0.01 & 1.70 & & & & \\
\hline Hepatitis B or C & 0.88 & & & & & & & \\
\hline No & & & Ref. & & & & & \\
\hline Yes & & 0.49 & 0.02 & 11.15 & & & & \\
\hline Not reported & & 0.47 & 0.01 & 27.36 & & & & \\
\hline Alcohol consumption (yes/no) & 0.66 & 1.86 & 0.12 & 28.92 & & & & \\
\hline Histology grade & 0.54 & & & & & & & \\
\hline G1-2 & & & Ref. & & & & & \\
\hline G3-4 & & 2.65 & 0.47 & 14.89 & & & & \\
\hline Not reported & & 0.45 & 0.00 & $2.64 \times 10^{171}$ & & & & \\
\hline New tumor event (yes/no) & 0.55 & $242,100.00$ & 0.00 & $6.504 \times 10^{22}$ & & & & \\
\hline Pathologic stage & 0.01 & & & & & & & \\
\hline Stage I+II & & & Ref. & & & & & \\
\hline Stage III+IV & & 23.11 & 3.14 & 169.93 & & & & \\
\hline Not reported & & 2.47 & 0.00 & $1.40 \times 10^{172}$ & & & & \\
\hline Cancer status & 0.91 & & & & & & & \\
\hline Tumor free & & & Ref. & & & & & \\
\hline With tumor & & 1.84 & 0.10 & 35.34 & & & & \\
\hline Not reported & & 1.84 & 0.03 & 125.06 & & & & \\
\hline Family cancer history & 0.33 & & & & & & & \\
\hline No & & & Ref. & & & & & \\
\hline Yes & & 1.07 & 0.12 & 9.75 & & & & \\
\hline Not reported & & 0.01 & 0.00 & 4.99 & & & & \\
\hline Residual tumor & 0.14 & & & & & & & \\
\hline R0 & & & Ref. & & & & & \\
\hline Non-R0 & & 255.36 & 1.10 & $59,270.00$ & & & & \\
\hline Vascular invasion & 0.82 & & & & & & & \\
\hline Negative & & & Ref. & & & & & \\
\hline Positive & & 1.80 & 0.01 & 273.16 & & & & \\
\hline
\end{tabular}

BMI, body mass index; AFP, $\alpha$-fetoprotein; HR, hazard ratio; CI, confidence interval; Ref., reference.

patients with or without fibrosis, and have greater specificity in HCC patients with fibrosis. Moreover, the DElncRNAs of risk scoring systems in the present study are different from those in previous studies. To the best of our knowledge, this is the first 

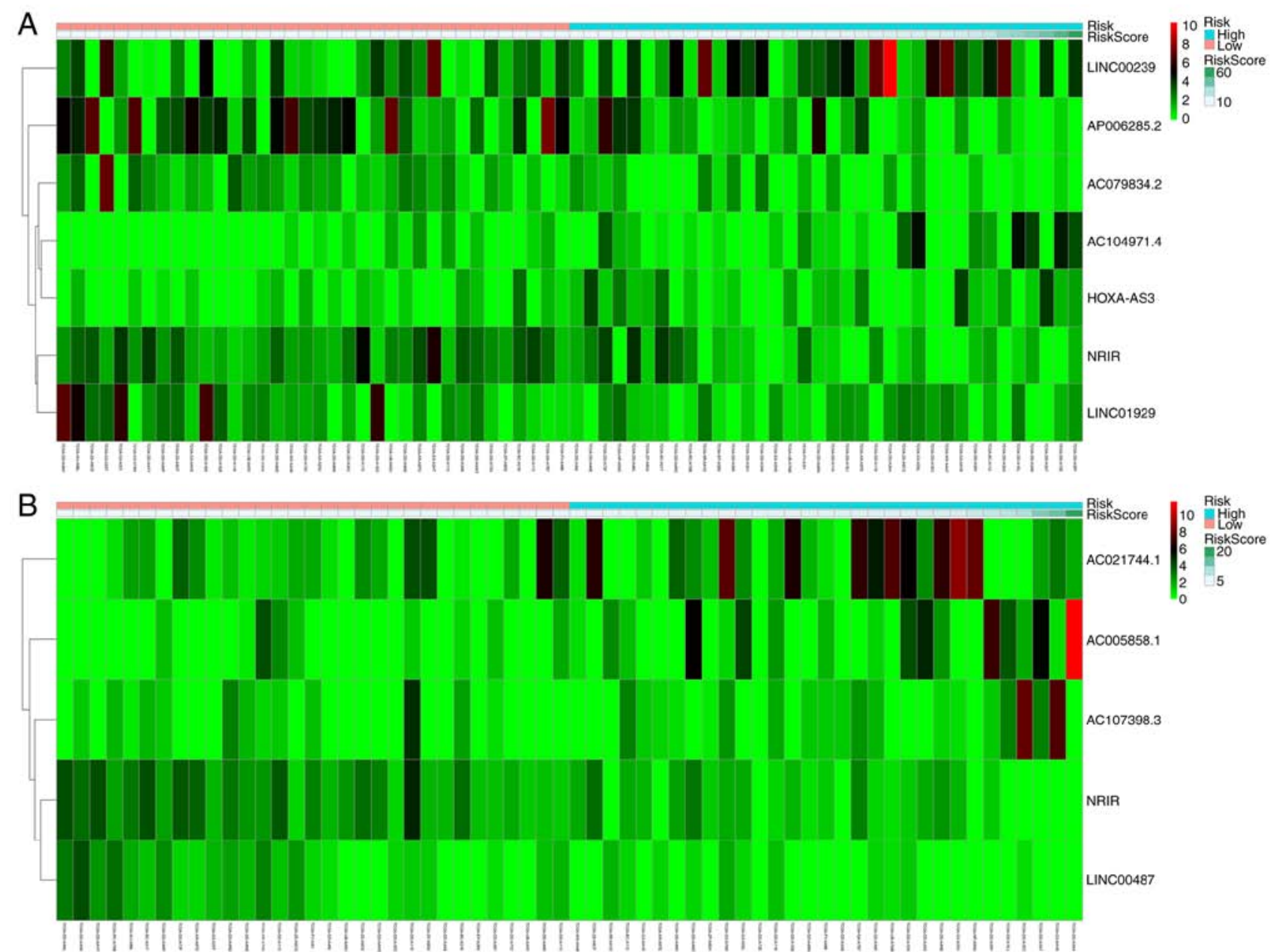

Figure 6. Non-cluster risk heat map of the risk scoring systems based on long non-coding RNA expression for (A) overall survival or (B) recurrence-free survival in hepatocellular carcinoma patients without fibrosis. Risk rises gradually from left to right.

A

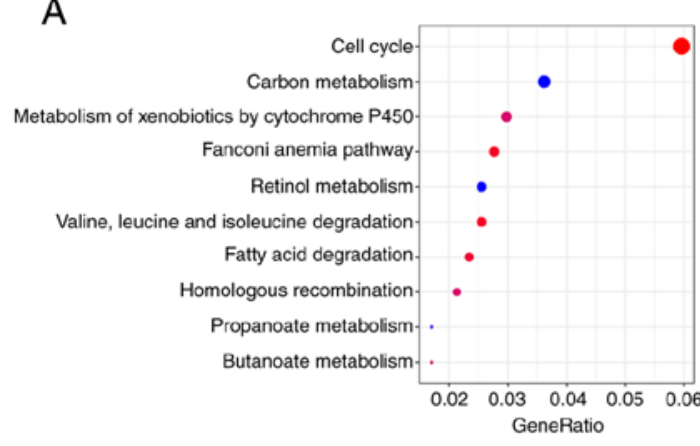

C

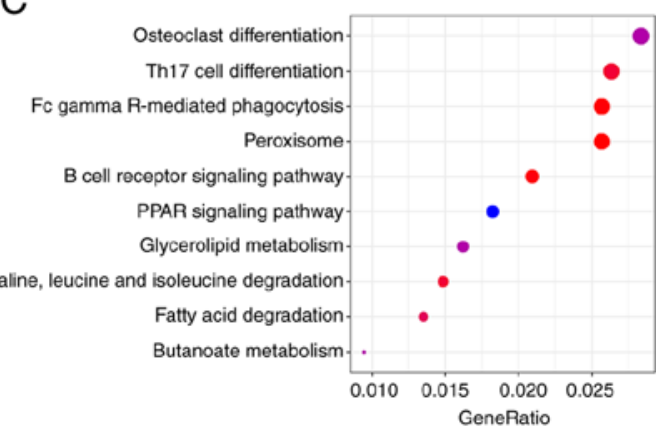

B

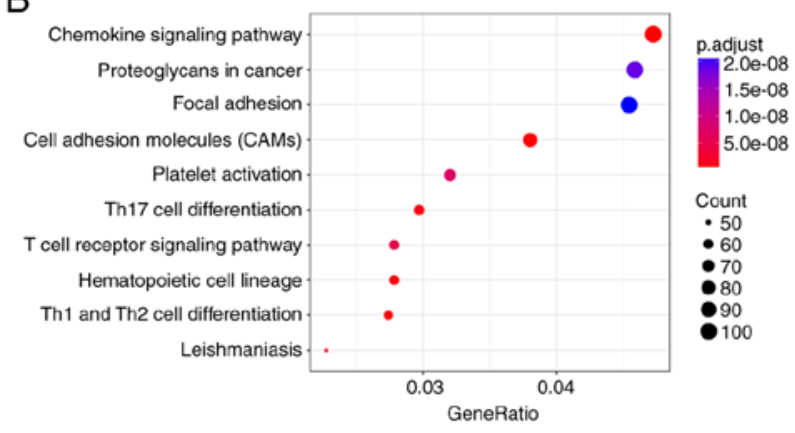

D

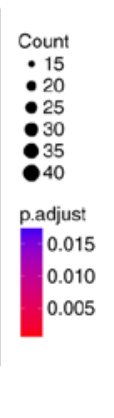

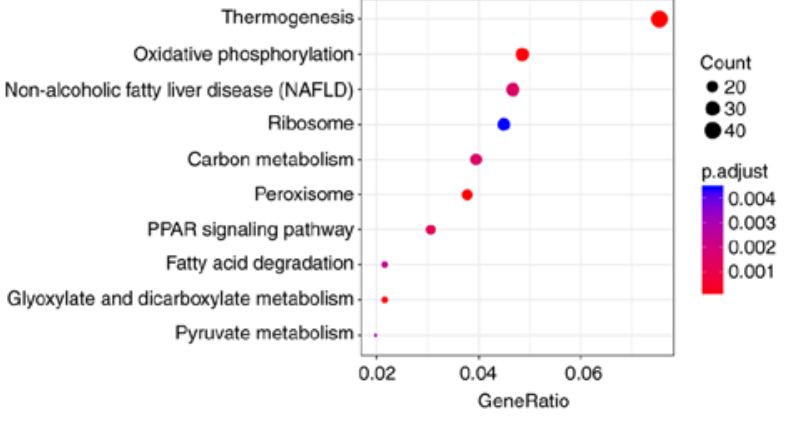

Figure 7. Top 10 significantly enriched Kyoto Encyclopedia of Genes and Genomes pathways of protein-coding genes strongly associated with the long non-coding RNAs used in the risk scoring systems to predict (A) OS or (B) RFS of HCC patients with fibrosis, and (C) OS or (D) RFS of HCC patients without fibrosis. OS, overall survival; RFS, recurrence-free survival; HCC, hepatocellular carcinoma. 
study to construct a risk scoring system to predict survival in HCC patients with or without fibrosis.

Despite its advantages, the present study has several limitations. First, the prognostic value of the lncRNAs in this study has not been validated in sample tissues or cells. Second, the multivariate Cox regression analysis did not include type of HCC treatment because these data were lacking from TCGA; treatment history may affect OS and RFS (32). Indeed, the adjustment for potential effects of other clinical characteristics on survival in the present study may have been biased because relevant data for some patients were not reported. Third, HCC patients were not stratified based on early or advanced fibrosis, which may have biased the results, such as the finding that the risk scoring system was not a significant predictor of RFS in HCC patients with fibrosis. Fourth, the hepatic fibrosis of patients in the TCGA database was evaluated using only the Ishak fibrosis score, which may be inaccurate.

Despite these limitations, the results describe novel risk scoring systems based on the expression of 5-7 lncRNAs for predicting the OS of HCC patients with or without fibrosis, and for predicting the RFS of patients without fibrosis. Further studies are required to explore the possibility of using lncRNA expression to predict the RFS of HCC patients with fibrosis.

\section{Acknowledgements}

Not applicable.

\section{Funding}

This study was supported by The Young and Middle-aged Teacher Basic Ability Enhancement Project of Guangxi University (grant no. 2018KY0111), and Innovation Project of Guangxi Graduate Education (no. YCBZ2019036).

\section{Availability of data and materials}

All the datasets generated and/or analyzed during the present study are included in this published article.

\section{Authors' contributions}

LG and JY conceived the study. JY and SW conducted the data curation and formal analysis. JY and SP were responsible for methodology. SP and JH were responsible for data collection. LG supervised the study. JY and JH were responsible for data visualization. JY drafted the manuscript and LG revised the manuscript. All authors read and approved the final manuscript.

\section{Ethics approval and consent to participate}

Not applicable.

\section{Patient consent for publication}

Not applicable.

\section{Competing interests}

The authors declare that they have no competing interests.

\section{References}

1. Forner A, Reig M and Bruix J: Hepatocellular carcinoma. Lancet 391: 1301-1314, 2018.

2. Bray F, Ferlay J, Soerjomataram I, Siegel RL, Torre LA and Jemal A: Global cancer statistics 2018: GLOBOCAN estimates of incidence and mortality worldwide for 36 cancers in 185 countries. CA Cancer J Clin 68: 394-424, 2018.

3. Fong ZV and Tanabe KK: The clinical management of hepatocellular carcinoma in the United States, Europe, and Asia: A comprehensive and evidence-based comparison and review. Cancer 120: 2824-2838, 2014.

4. Bruix J, Gores GJ and Mazzaferro V: Hepatocellular carcinoma: Clinical frontiers and perspectives. Gut 63: 844-855, 2014.

5. Ponting CP, Oliver PL and Reik W: Evolution and functions of long noncoding RNAs. Cell 136: 629-641, 2009.

6. Wu L, Pan C, Wei X, Shi Y, Zheng J, Lin X and Shi L: IncRNA KRAL reverses 5-fluorouracil resistance in hepatocellular carcinoma cells by acting as a ceRNA against miR-141. Cell Commun Signal 16: 47, 2018.

7. Huang Y, Xiang B, Liu Y, Wang Y and Kan H: LncRNA CDKN2B-AS1 promotes tumor growth and metastasis of human hepatocellular carcinoma by targeting let-7c-5p/NAP1L1 axis. Cancer Lett 437: 56-66, 2018.

8. Schmitt AM and Chang HY: Long noncoding RNAs in cancer pathways. Cancer Cell 29: 452-463, 2016.

9. Song YX, Sun JX, Zhao JH, Yang YC, Shi JX, Wu ZH, Chen XW Gao P, Miao ZF and Wang ZN: Non-coding RNAs participate in the regulatory network of CLDN4 via ceRNA mediated miRNA evasion. Nat Commun 8: 289, 2017.

10. Liu Y, Feng J, Sun M, Yang G, Yuan H, Wang Y, Bu Y, Zhao M, Zhang $S$ and Zhang $X$ : Long non-coding RNA HULC activates $\mathrm{HBV}$ by modulating $\mathrm{HBx} / \mathrm{STAT} 3 / \mathrm{miR}-539 / \mathrm{APOBEC} 3 \mathrm{~B}$ signaling in HBV-related hepatocellular carcinoma. Cancer Lett 454: 158-170, 2019.

11. Jiang R, Tang J, Chen Y, Deng L, Ji J, Xie Y, Wang K, Jia W, Chu WM and Sun B: The long noncoding RNA lnc-EGFR stimulates T-regulatory cells differentiation thus promoting hepatocellular carcinoma immune evasion. Nat Commun 8: 15129, 2017.

12. Friedman SL: Evolving challenges in hepatic fibrosis. Nat Rev Gastroenterol Hepatol 7: 425-436, 2010.

13. Takaya H, Kawaratani H, Tsuji Y, Nakanishi K, Saikawa S, Sato S, Sawada Y, Kaji K, Okura Y, Shimozato N, et al: von Willebrand factor is a useful biomarker for liver fibrosis and prediction of hepatocellular carcinoma development in patients with hepatitis B and C. United European Gastroenterol J 6: 1401-1409, 2018.

14. O'Rourke JM, Sagar VM, Shah T and Shetty S: Carcinogenesis on the background of liver fibrosis: Implications for the management of hepatocellular cancer. World J Gastroenterol 24: 4436-4447, 2018.

15. Ko CJ, Lin PY, Lin KH, Lin CC and Chen YL: Presence of fibrosis is predictive of postoperative survival in patients with small hepatocellular carcinoma. Hepatogastroenterology 61: 2295-2300, 2014.

16. Kadri HS, Blank S, Wang Q, Kim KW, Fiel MI, Luan W and Hiotis SP: Outcomes following liver resection and clinical pathologic characteristics of hepatocellular carcinoma occurring in patients with chronic hepatitis B and minimally fibrotic liver. Eur J Surg Oncol 39: 1371-1376, 2013.

17. Hung HH, Su CW, Lai CR, Chau GY, Chan CC, Huang YH, Huo TI, Lee PC, Kao WY, Lee SD and Wu JC: Fibrosis and AST to platelet ratio index predict post-operative prognosis for solitary small hepatitis B-related hepatocellular carcinoma. Hepatol Int 4: 691-699, 2010.

18. Abdalla AF, Zalata KR, Ismail AF, Shiha G, Attiya M and Abo-Alyazeed A: Regression of fibrosis in paediatric autoimmune hepatitis: Morphometric assessment of fibrosis versus semiquantiatative methods. Fibrogenesis Tissue Repair 2: 2, 2009.

19. Robinson MD, McCarthy DJ and Smyth GK: edgeR: A Bioconductor package for differential expression analysis of digital gene expression data. Bioinformatics 26: 139-140, 2010.

20. Yu G, Wang LG, Han Y and He QY: clusterProfiler: An R package for comparing biological themes among gene clusters. Omics 16: 284-287, 2012.

21. Artinyan A, Mailey B, Sanchez-Luege N, Khalili J, Sun CL, Bhatia S, Wagman LD, Nissen N, Colquhoun SD and Kim J: Race, ethnicity, and socioeconomic status influence the survival of patients with hepatocellular carcinoma in the United States. Cancer 116: 1367-1377, 2010. 
22. Shebl FM, Capo-Ramos DE, Graubard BI, McGlynn KA and Altekruse SF: Socioeconomic status and hepatocellular carcinoma in the United States. Cancer Epidemiol Biomarkers Prev 21: 1330-1335, 2012.

23. Liu H, Cen D, Yu Y, Wang Y, Liang X, Lin H and Cai X: Does fibrosis have an impact on survival of patients with hepatocellular carcinoma: Evidence from the SEER database? BMC Cancer 18: $1125,2018$.

24. Yan J, Zhou C, Guo K, Li Q and Wang Z: A novel seven-lncRNA signature for prognosis prediction in hepatocellular carcinoma. J Cell Biochem 120: 213-223, 2019.

25. Zhao QJ, Zhang J, Xu L and Liu FF: Identification of a five-long non-coding RNA signature to improve the prognosis prediction for patients with hepatocellular carcinoma. World J Gastroenterol 24: 3426-3439, 2018.

26. Wu Y, Wang PS, Wang BG, Xu L, Fang WX, Che XF, Qu XJ, Liu YP and Li Z: Genomewide identification of a novel six-LncRNA signature to improve prognosis prediction in resectable hepatocellular carcinoma. Cancer Med 7: 6219-6233, 2018.

27. Sui J, Miao Y, Han J, Nan H, Shen B, Zhang X, Zhang Y, Wu Y, Wu W, Liu T, et al: Systematic analyses of a novel lncRNA-associated signature as the prognostic biomarker for hepatocellular carcinoma. Cancer Med: May 15, 2018 (Epub ahead of print). doi: $10.1002 /$ cam4.1541.
28. Shi YM, Li YY, Lin JY, Zheng L, Zhu YM and Huang J: The discovery of a novel eight-mRNA-lncRNA signature predicting survival of hepatocellular carcinoma patients. J Cell Biochem: Nov 28, 2018 (Epub ahead of print). doi: 10.1002/jcb.28028.

29. Ma Y, Luo T, Dong D, Wu X and Wang Y: Characterization of long non-coding RNAs to reveal potential prognostic biomarkers in hepatocellular carcinoma. Gene 663: 148-156, 2018.

30. Liao X, Yang C, Huang R, Han C, Yu T, Huang K, Liu X, Yu L, $\mathrm{Zhu} \mathrm{G}, \mathrm{Su} \mathrm{H}$, et al: Identification of potential prognostic long non-coding RNA biomarkers for predicting survival in patients with hepatocellular carcinoma. Cell Physiol Biochem 48: 1854-1869, 2018.

31. Gu J, Zhang X, Miao R, Ma X, Xiang X, Fu Y, Liu C, Niu W and Qu K: A three-long non-coding RNA-expression-based risk score system can better predict both overall and recurrence-free survival in patients with small hepatocellular carcinoma. Aging (Albany NY) 10: 1627-1639, 2018.

32. El-Serag HB, Siegel AB, Davila JA, Shaib YH, Cayton-Woody M, McBride R and McGlynn KA: Treatment and outcomes of treating of hepatocellular carcinoma among medicare recipients in the United States: A population-based study. J Hepatol 44: 158-166, 2006.

This work is licensed under a Creative Commons Attribution-NonCommercial-NoDerivatives 4.0 International (CC BY-NC-ND 4.0) License. 